\title{
"Relief-Retaining" Control Technology of Floor Heave in Mining Roadway with Soft Rock: A Case Study
}

\author{
Ai Chen $\left(\mathbb{D},{ }^{1,2}\right.$ Xuebin Li $\left(\mathbb{D},{ }^{1}\right.$ Xuesheng Liu $\mathbb{D},{ }^{1}$ Yunliang Tan $\left(\mathbb{D},{ }^{1}\right.$ Ke Xu $\mathbb{D}$, ${ }^{1}$ \\ and Honglei Wang $\mathbb{1}^{1}$ \\ ${ }^{1}$ School of Energy and Mining Engineering, Shandong University of Science and Technology, Qingdao 266590, China \\ ${ }^{2}$ Ningxia Coal Industry Co., Ltd., of China Energy Group, Yinchuan 750000, China \\ Correspondence should be addressed to Xuesheng Liu; xuesheng1134@163.com
}

Received 1 October 2021; Revised 28 October 2021; Accepted 5 November 2021; Published 23 November 2021

Academic Editor: Lingkun Chen

Copyright (C) 2021 Ai Chen et al. This is an open access article distributed under the Creative Commons Attribution License, which permits unrestricted use, distribution, and reproduction in any medium, provided the original work is properly cited.

\begin{abstract}
The floor heave problem is one of the important factors affecting the stability and safety of surrounding rocks of roadways, especially in deep high-stress mining roadway with soft rock. The return airway of no. 130203 working face in Zaoquan Coal Mine of Ningdong Mining Area in Northwest China is the research object in this study. Firstly, an innovative "relief-retaining" control scheme of floor heave is proposed, which is the comprehensive measure of "cutting groove in floor + drilling for pressure relief at roadway side + setting retaining piles at the junction of roadway side and floor." Then, the specific parameters suitable for floor heave control of no. 130203 return airway are determined using numerical simulation method. Finally, the yield monitoring results show that both the deformation of surrounding rocks and the cable force are significantly reduced. The roof falling capacity, floor heave displacement, and thickness increasing value of 0-2 m floor strata are $596 \mathrm{~mm}, 410 \mathrm{~mm}$, and $82 \mathrm{~mm}$, respectively, which are $43.67 \%, 67.49 \%$, and $75.38 \%$ less than those of the control section. The maximum force of cables at roadway sides is $140.13 \mathrm{kN}$, about $32.54 \%$ less than that of the control section. The results verify the reliability of the proposed "reliefretaining" control scheme and can provide some reference for the floor heave control of similar roadways.
\end{abstract}

\section{Introduction}

After excavation of mining roadway, the phenomenon of upward heave of roadway floor is called floor heave. Floor heave will reduce the roadway section, hinder pedestrians and transportation, and hinder the mine ventilation. Many mines have to invest a lot of manpower and material resources to do temporary processing work such as "digging the bottom." Seriously, it will cause the whole roadway to be scrapped and affect the safety of mine production [1-5]. Therefore, it is of great significance to study the floor heave control of mining roadway.

In order to control the floor heave problem effectively, many scholars have conducted a lot of exploration, and many floor heave prevention and control technologies are proposed. For example, He et al. [6] proposed the bolt, steel mesh, and anchor coupling support technology for the floor heave of deep coal roadway, which controlled the large deformation and floor heave of deep coal roadway effectively. Sun and Wang [7] studied the control method of floor heave by the way of roadway cutting groove to relieve pressure, which improved the stress state of the floor effectively. Aiming at the deformation and failure characteristics of mining roadway, Bai et al. [8] put forward to strengthen the floor and reduce the stress environment of surrounding rocks for the control measures of floor heave, and the control effect is remarkable. Li [9] proposed reinforcement floor and bottom angle control method for floor heave of roadway, which laid the foundation for further study of floor heave control. Wang et al. [10] studied the floor heave control method of high-stress soft rock roadway, took the triple roadway of the main belt conveyor roadway in the west wing of Panyidong Mine as the research object, and proposed the floor heave control scheme based on end anchor cable bundle, which provided solutions and ideas for the floor heave problem of high-stress soft rock roadway. Chen et al. [11] proposed the floor heave control technology of soft rock roadway with "floor anchor + floor 
hardening + relief groove + roof and side anchor (cable) supplement" and achieved good engineering application results. Wang et al. [12] proposed the support concept of strong bottom reinforcement and modified the support parameters in a timely manner by dynamic analysis according to the degree of floor heave, which provided a theoretical basis for the treatment of floor heave. Stankus and Peng [13] proposed the supporting theory of coupling of yielding support and rigid support and designed and applied the retractable floor beam, which achieved good economic and technical results. Many scholars have done a lot of research on floor heave control, mainly focused on the aspects of reducing surrounding rocks stress [14-17] and increasing floor integrity [18-23], and achieved good control results.

However, due to the complex diagenetic conditions of Ningdong Mining Area in northwest China, the cohesion of coal and rock is low, the internal friction angle is small, the stress level of surrounding rocks is high, the roadway floor has continuous deformation, and the floor heave is very large [24-27]. The application effect of the existing floor heave control method in Ningdong Mining Area is limited. The method of floor heave control suitable for high-stress roadway with soft rock needs further exploration, especially in Ningdong Mining Area.

Based on the typical large deformation roadway with soft rock in Zaoquan Coal Mine of Ningdong Mining Area, this paper puts forward the innovative "relief-retaining" control scheme of floor heave, and the specific parameters suitable for floor heave control of no. 130203 return airway are determined using numerical simulation method. Field monitoring results verify the reliability of the proposed "relief-retaining" control scheme and can provide some reference for the floor heave control of similar roadways.

\section{Engineering Background}

Zaoquan Coal Mine in Ningdong Mining Area, as the main production mine of Ningmei Group with an annual output of 8 million tons, is located at the edge of Maowusu Desert $62 \mathrm{~km}$ southeast of Lingwu City, Ningxia, and the specific geographical location is shown in Figure 1. The length of the minefield is $13 \mathrm{~km}$ from north to south, and the width from east to west is about $4 \mathrm{~km}$ on average. The minefield area is $56.6982 \mathrm{~km}^{2}$, and the geological reserves are 10.6574 million tons.

The research object of this paper is no. 130203 return airway in Zaoquan Coal Mine. The depth of roadway is $670 \mathrm{~m}$, the vertical stress is about $16.75 \mathrm{MPa}$, the recoverable length of strike is $2832 \mathrm{~m}$, and the inclined length is $198 \sim 225 \mathrm{~m}$. There are 5 15 m coal pillars on the east side of the working face adjacent to the goaf of no. 130202 working face. The west side is the no. 130205 preparation face under excavation, the south side is the undeveloped area, and the north side is the extension section of 13 mining areas. Through the in situ stress test of the return airway in 130203 working face, the results show that the maximum horizontal principal stress of the roadway is $11.65 \mathrm{MPa}$, which belongs to the area of medium stress value.
The strata of no. 130203 working face coal seam are Middle Jurassic Yan'an Formation. The floor is a typical soft stratum, which is mainly the carbonaceous mudstone and argillaceous sandstone, and the uniaxial strength is between $17 \mathrm{MPa}$ and $23 \mathrm{MPa}$. The soft strata of the floor lead to the serious floor heave problem of the roadway under the influence of the high surrounding rocks stress of the floor during the tunneling and mining of the no. 130203 roadway, which affects the normal mining of the mine. The floor heave deformation of the roadway is shown in Figure 2.

\section{3. "Relief-Retaining" Control Scheme of Floor Heave}

\subsection{Control Scheme}

3.1.1. Cutting Groove in the Floor. The loose pressure relief groove is arranged near the center of roadway floor in the test area. In order to minimize the disturbance of surrounding rocks outside the pressure relief groove, the pressure relief groove is produced by smooth blasting, and the sectional drawing and vertical view are as shown in Figure 3.

3.1.2. Setting Retaining Piles at the Junction of Roadway Side and Floor. The retaining pile is inclined to the outside of the roadway at a certain angle in the horizontal direction. The retaining pile is made of steel pipe, cement, and sodium silicate slurry. By drilling a hole at a predetermined position, installing a steel pipe in the hole and installing an anchor cable inside the steel pipe, injecting cement and water glass, and then applying a certain preload to the anchor cable after solidification, the fabrication of retaining pile can be completed. The sectional drawing and vertical view are as shown in Figure 4.

3.1.3. Drilling for Pressure Relief at Roadway Side. Large-diameter pressure relief boreholes are arranged in the solid coal side to transfer the peak value of lateral abutment pressure to the deep coal side. At a certain height from the floor of the roadway, two rows of large-diameter boreholes are constructed along the roadway direction, which are arranged in three-flower-hole layout. For the convenience of site construction, a certain elevation angle can be brought in the borehole construction. The borehole diameter is generally $130 \mathrm{~mm}$, and the sectional drawing and vertical view are as shown in Figure 5.

\subsection{Parameter Selection}

3.2.1. Simulation Scheme and Modeling. The "relief-retaining" control scheme of floor heave mainly involves the following parameters: the depth and width of pressure relief grooves, the length and spacing of retaining pile, and the depth and spacing of large-diameter pressure relief boreholes in solid coal side. By comparing the construction examples of mines with similar geological conditions, the numerical simulation scheme is shown in Table 1. Physical 


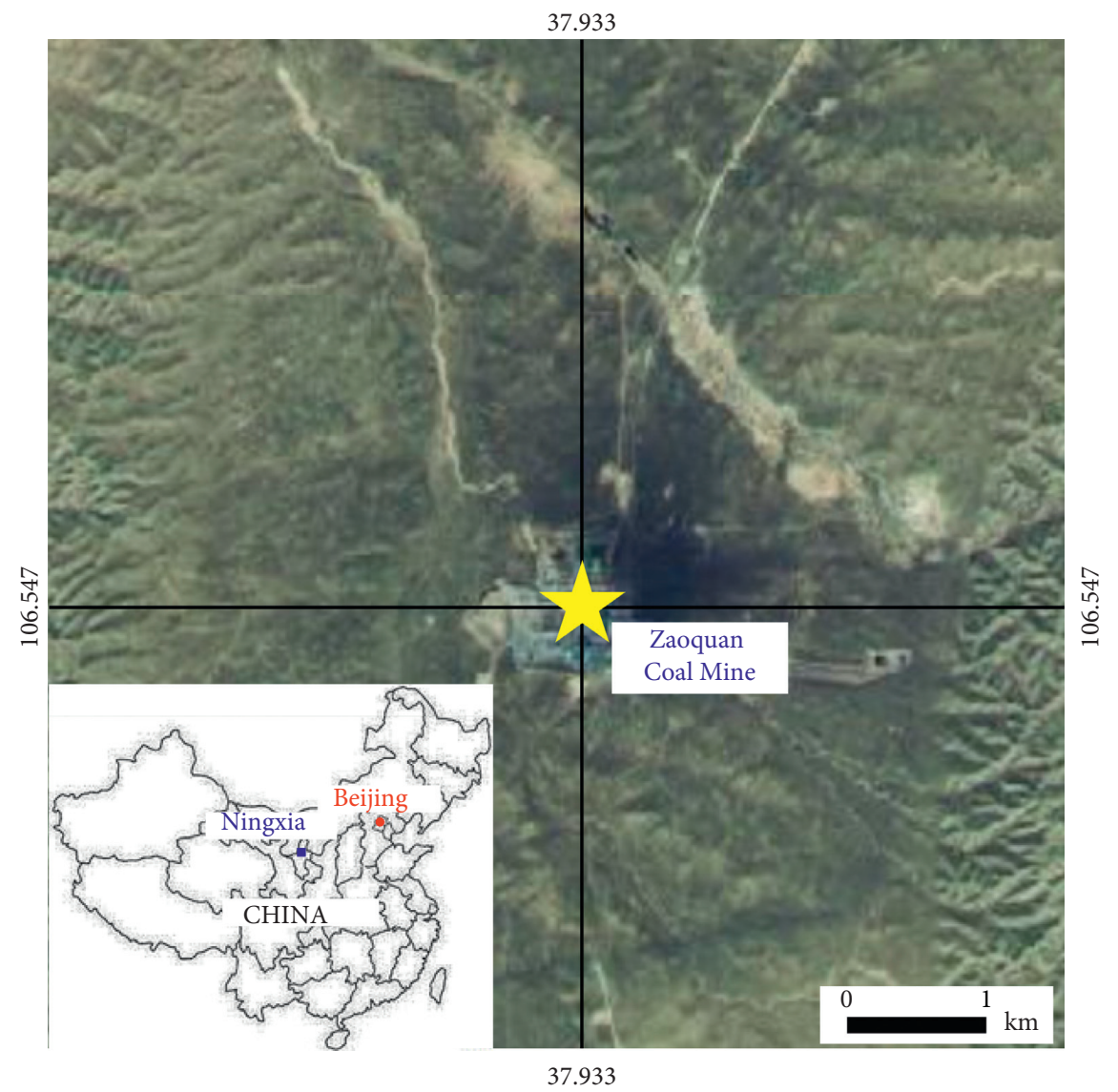

FIgURE 1: Floor heave of return airway in no. 130203 working face.

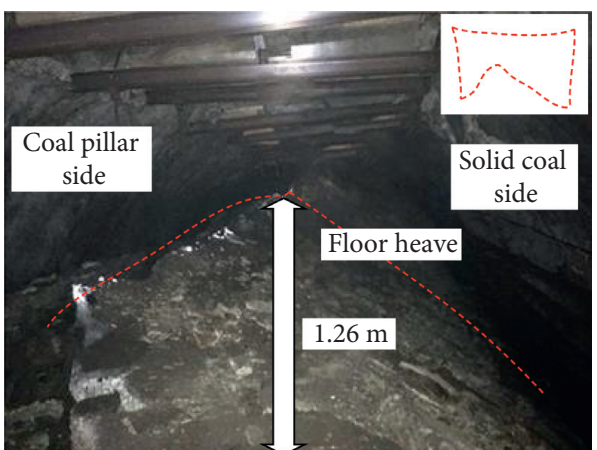

FIGURE 2: Floor heave of return airway in no. 130203 working face.

and mechanical parameters of retaining pile are shown in Table 2.

This section takes the geological and mining conditions of no. 130203 return airway in Zaoquan Coal Mine as the background, adopts FLAC3D numerical software, selects no. 130203 working face as the engineering prototype, and selects the length of $X$ horizontal direction $200 \mathrm{~m}$, the length of $Y$ horizontal direction $50 \mathrm{~m}$, and the length of $Z$ vertical direction $150 \mathrm{~m}$ to establish the numerical calculation model. The coarse sandstone is the upper boundary of the model, and the medium sandstone is the lower boundary of the model. The strata from top to bottom are coarse sandstone, siltstone, coal, mudstone, fine sandstone, and medium sandstone. The buried depth of field roadway is about $700 \mathrm{~m}$, and $17.5 \mathrm{MPa}$ uniform compressive stress is applied on the upper boundary of the model. The specific shape of roadway section is selected as rectangular roadway, and the roadway size is $5.0 \mathrm{~m} \times 4.0 \mathrm{~m}$. The specific model is shown in Figure 6.

The left and right, front and back, and lower boundaries of the model are displacement boundaries, and the top of the model is stress boundary conditions. The mechanical parameters of coal and rock in the model are shown in Table 3.

\subsubsection{Modeling Results}

(1) Cutting Groove in the Floor. The deformation and stress distribution of roadway surrounding rocks with different width of cutting grooves in the floor are shown in Figure 7.

It can be seen from Figure 7 that when the depth of cutting groove is constant, with the increase of the width of cutting groove, the deformation compensation space of the floor surrounding rocks increases, and the floor heave displacement of the roadway decreases gradually. In particular, when the width of cutting groove is not more than $0.6 \mathrm{~m}$, the floor heave displacement decreases rapidly. When the width of cutting groove is more than $0.6 \mathrm{~m}$, the floor heave displacement decreases slowly with the increase of the width of cutting groove. It can be seen that when the cutting 


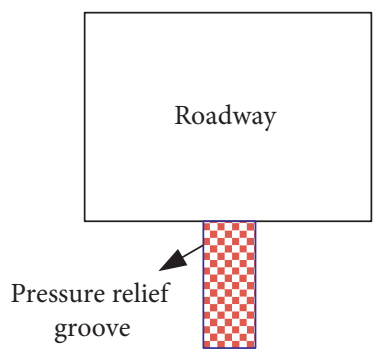

(a)

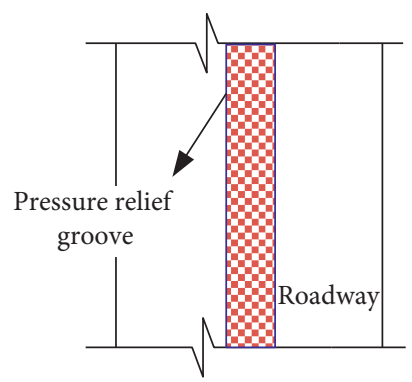

(b)

FIGURE 3: Schematic diagram of cutting groove in the floor. (a) Sectional drawing; (b) vertical view.

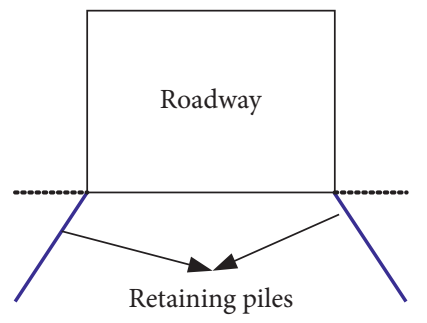

(a)

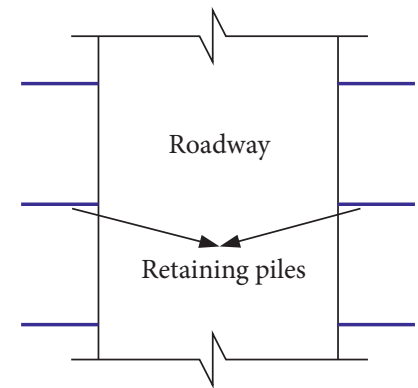

(b)

FIgURE 4: Indication diagram of retaining pile arrangement. (a) Sectional drawing; (b) vertical view.

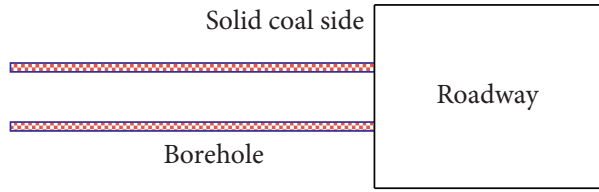

(a)

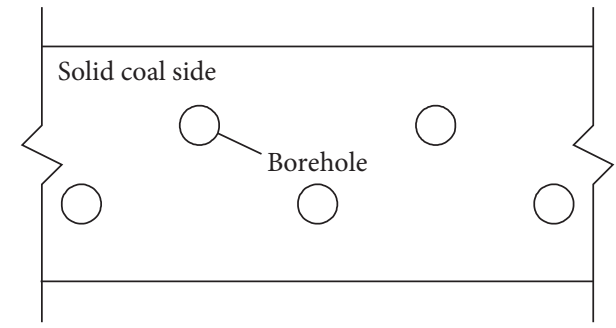

(b)

FIgURE 5: Large-diameter pressure relief drilling schematic diagram of solid coal side. (a) Sectional drawing; (b) vertical view.

TABLE 1: Numerical simulation scheme for control scheme of floor heave.

\begin{tabular}{lcccc}
\hline \multicolumn{1}{c}{ Control technologies and parameters } & Scheme 1 & Scheme 2 & Scheme 3 \\
\hline \multirow{2}{*}{ Pressure relief grooves } & Depth $(\mathrm{m})$ & 2.0 & 2.0 & 0.6 \\
& Width $(\mathrm{m})$ & 0.4 & 3.0 & 0.8 \\
\hline \multirow{2}{*}{ Retaining piles } & Depth $(\mathrm{m})$ & 3.0 & 3.0 \\
& Spacing $(\mathrm{m})$ & 0.5 & 1.0 & 1.5 \\
\hline \multirow{2}{*}{ Large-diameter pressure relief boreholes } & Depth $(\mathrm{m})$ & 10 & 10 \\
& Spacing $(\mathrm{m})$ & 0.8 & 1.0 \\
\hline
\end{tabular}

groove is set to control the floor heave, the width of cutting groove should not exceed $0.6 \mathrm{~m}$.

(2) Setting Retaining Piles at the Junction of Roadway Side and Floor. The deformation and stress nephogram of roadway surrounding rocks with different spacings of retaining piles are shown in Figure 8.
From Figure 8, it can be seen that the floor heave displacement increases with the increase of the spacing of retaining piles, and the increase trend decreases gradually. When the spacing of retaining piles exceeds $1.0 \mathrm{~m}$, the increase of the spacing of retaining piles has little effect on the improvement of floor heave control. From the economic point of view, too small spacing of retaining piles will also 
TABLE 2: Physical and mechanical parameters of retaining pile.

\begin{tabular}{lcccc}
\hline Name & Diameter $(\mathrm{mm})$ & Density $\left(\mathrm{kg} \cdot \mathrm{m}^{-3}\right)$ & Elastic modulus $(\mathrm{GPa})$ & Poisson ratio \\
\hline Retaining piles & 50 & 2500 & 35 & 0.2 \\
\hline
\end{tabular}

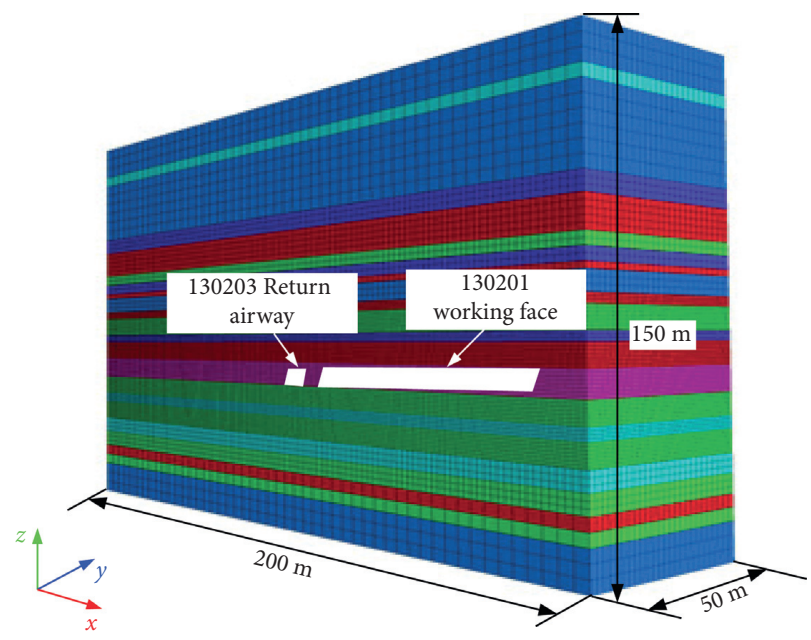

Figure 6: Numerical calculation model diagram of no. 130203 working face.

TABLe 3: Physical and mechanical parameter table of numerical model materials.

\begin{tabular}{lcccccc}
\hline Lithology & $\begin{array}{c}\text { Density } \\
\left(\mathrm{kg} \cdot \mathrm{m}^{-3}\right)\end{array}$ & $\begin{array}{c}\text { Compressive } \\
\text { strength }(\mathrm{MPa})\end{array}$ & $\begin{array}{c}\text { Tensile } \\
\text { strength } \\
(\mathrm{MPa})\end{array}$ & $\begin{array}{c}\text { Elastic } \\
\text { modulus } \\
(\mathrm{GPa})\end{array}$ & $\begin{array}{c}\text { Internal } \\
\text { cohesion }(\mathrm{MPa})\end{array}$ & $\begin{array}{c}\text { Internal } \\
\text { friction angle } \\
\left(^{\circ}\right)\end{array}$ \\
$\begin{array}{l}\text { Medium grained } \\
\text { sandstone }\end{array}$ & 2300 & 21.76 & 0.61 & 11.73 & 1.62 & 32 \\
$\begin{array}{l}\text { Gritstone } \\
\text { Siltstone }\end{array}$ & 2360 & 28.39 & 0.83 & 21.35 & 1.83 & 36 \\
Mudstone & 2860 & 27.62 & 0.71 & 19.04 & 1.24 & 37 \\
$\begin{array}{l}\text { Fine-sandstone } \\
\text { Carbon }\end{array}$ & 2620 & 17.36 & 0.56 & 9.60 & 0.86 & 34 \\
mudstone & 2510 & 23.30 & 0.96 & 14.37 & 1.36 & 0.25 \\
Coal & 2650 & 17.36 & 0.56 & 8.03 & 0.47 & 0.23 \\
Siltstone & 1310 & 11.65 & 0.47 & 8.71 & 0.50 & 27.25 \\
\hline
\end{tabular}

cause the increase of floor heave control cost. Therefore, the simulation of the spacing of retaining piles in the no. 130203 working face of Zaoquan Coal Mine in Ningdong Mining Area shows that the spacing of retaining piles is $1.0 \mathrm{~m}$.

(3) Drilling for Pressure Relief at Roadway Side. The deformation and stress nephogram of surrounding rocks of roadway with different spacings of pressure relief boreholes are shown in Figure 9.

Figure 9 shows that the floor heave displacement increases with the increase of the spacing of pressure relief boreholes, and the increasing trend decreases gradually. When the spacing of pressure relief boreholes exceeds $1.0 \mathrm{~m}$, the effect of pressure relief boreholes on floor heave control is not obvious. At the same time, when the spacing is reduced, the setting of dense drilling will further increase the control cost. Therefore, considering the control cost and control effect, the spacing of pressure relief boreholes in no. 130203 working face of Zaoquan Coal Mine in Ningdong Mining Area is $1.0 \mathrm{~m}$.
In summary, the main parameters for determining the "relief-retaining" control scheme of floor heave are as follows: the depth and width of pressure relief groove are $2.0 \mathrm{~m}$ and $0.5 \mathrm{~m}$, respectively. The length and spacing of retaining piles are $3.0 \mathrm{~m}$ and $1.0 \mathrm{~m}$, respectively. The depth and spacing of large-diameter pressure relief boreholes at the roadway side are $10.0 \mathrm{~m}$ and $1.0 \mathrm{~m}$, respectively.

\section{Analysis of Result}

The scheme is implemented outside $200 \mathrm{~m}$ of advanced working face, and the roadway with similar geological structure, surrounding rocks property, and coal pillar sizes should be selected for test. The length of the test area is $200 \mathrm{~m}$. The test area division and the corresponding station layout are shown in Figure 10. The original support scheme was used as the control section in the first $100 \mathrm{~m}$, and the last $100 \mathrm{~m}$ was the test section of the "relief-retaining" control scheme of floor heave in this paper. The monitoring results are as follows. 


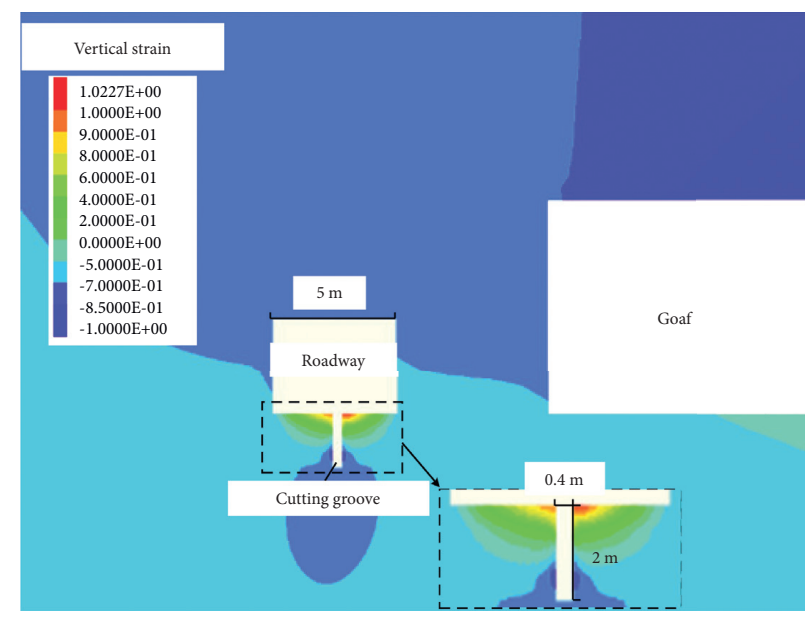

(a)

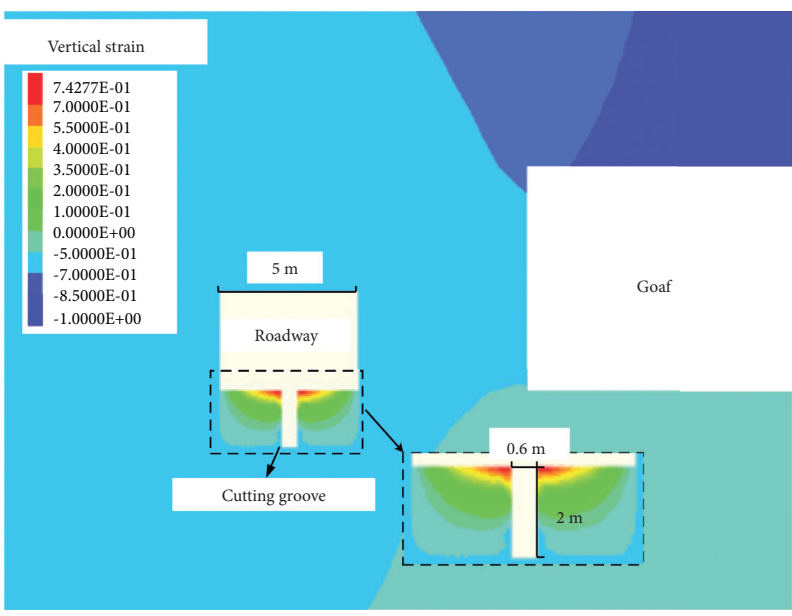

(c)

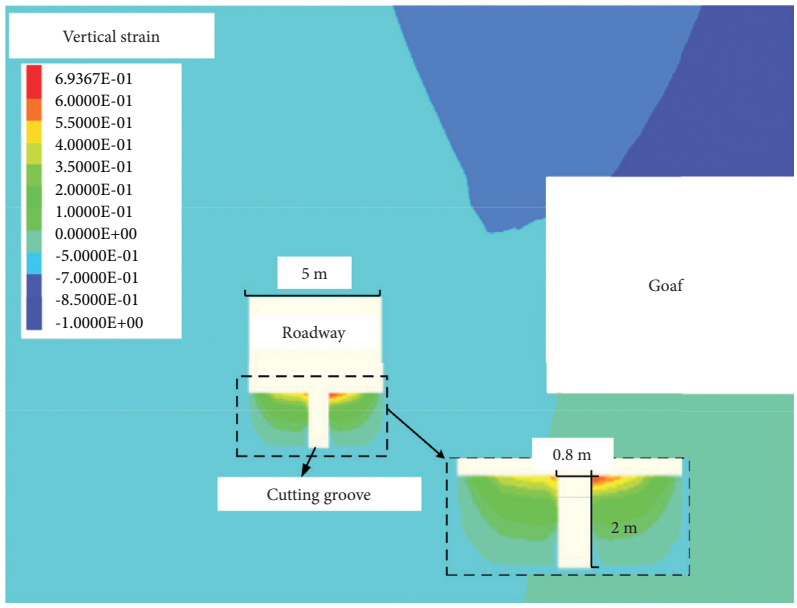

(e)

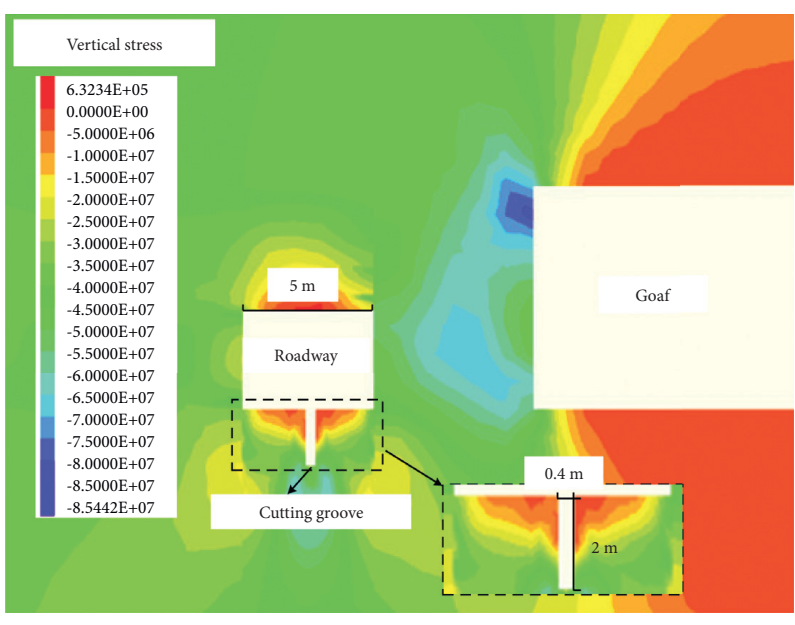

(b)

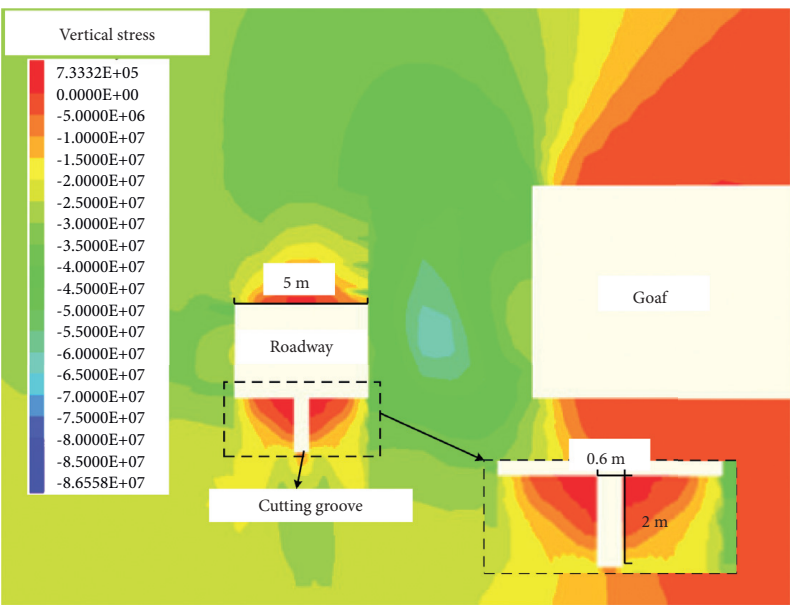

(d)

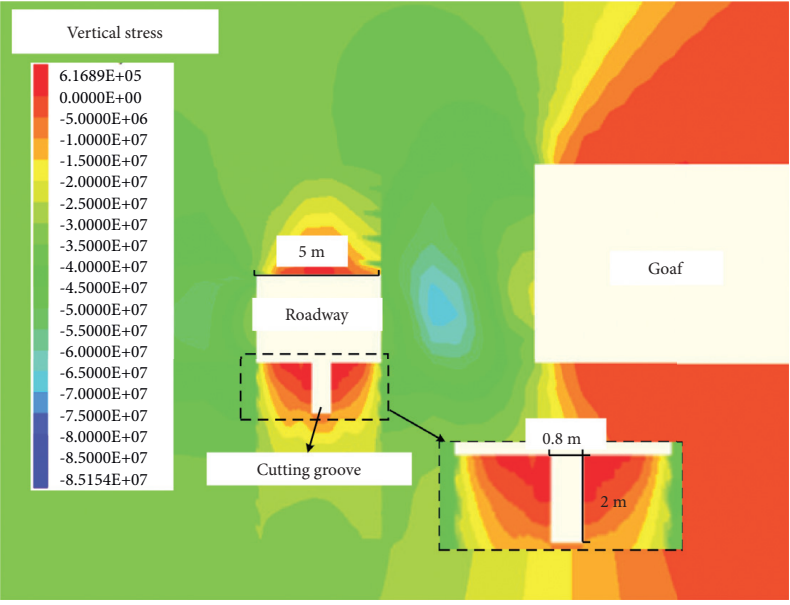

(f)

FIGURE 7: Deformation and stress distribution of roadway surrounding rock with different floor cutting groove width. (a) Vertical strain of $0.4 \mathrm{~m}$; (b) vertical stress of $0.4 \mathrm{~m}$; (c) vertical strain of $0.6 \mathrm{~m}$; (d) vertical stress of $0.6 \mathrm{~m}$; (e) vertical strain of $0.8 \mathrm{~m}$; (f) vertical strain of $0.8 \mathrm{~m}$. 


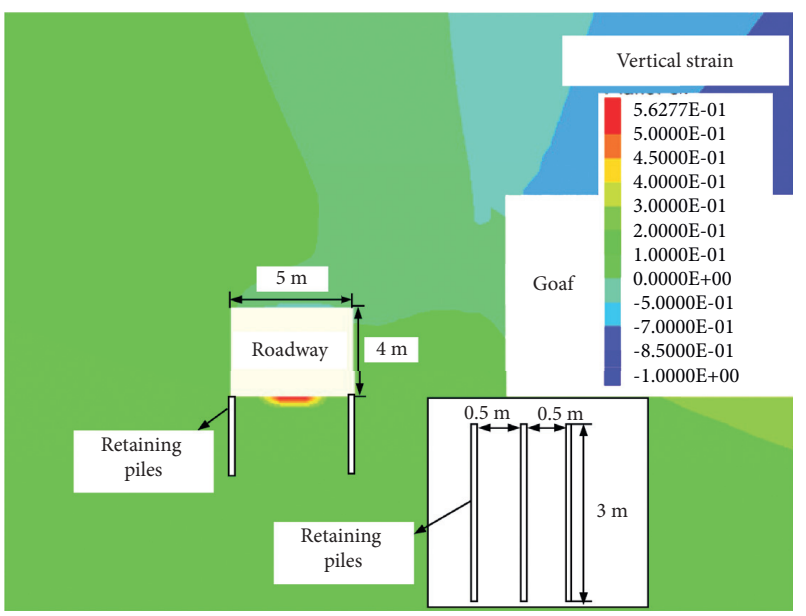

(a)

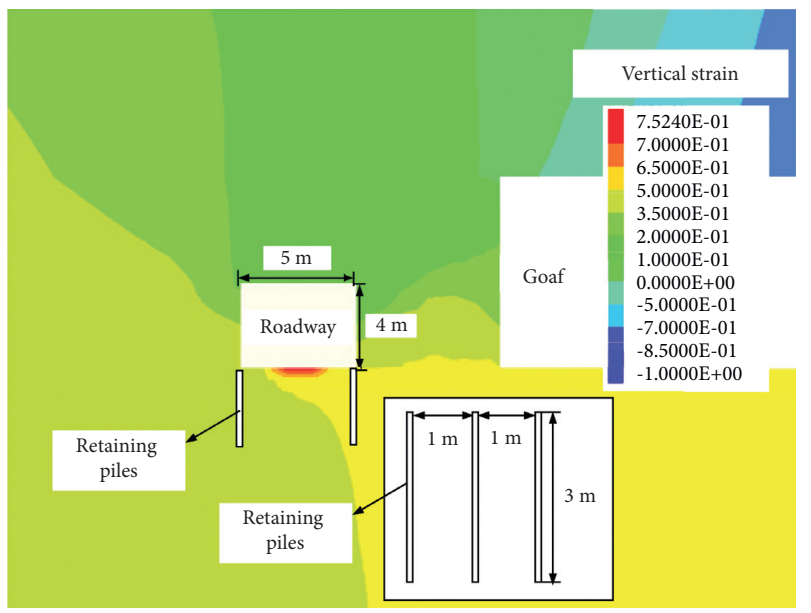

(c)

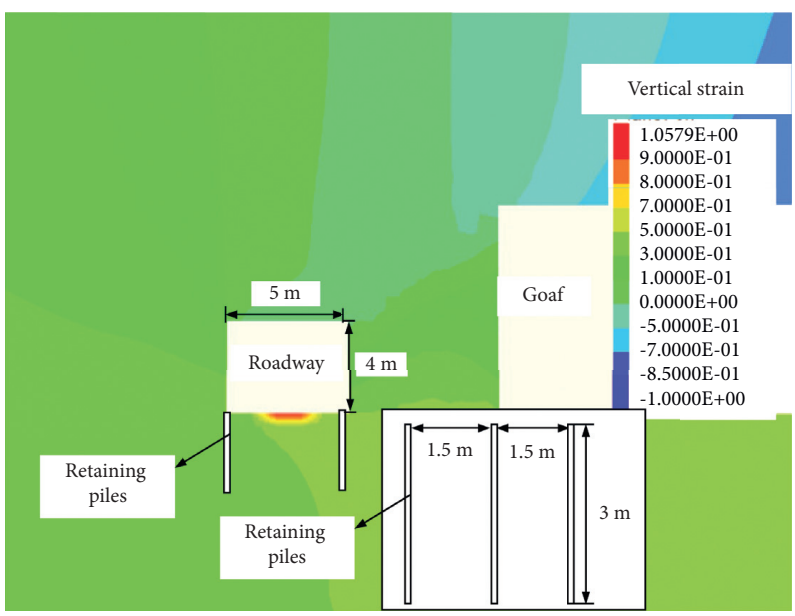

(e)

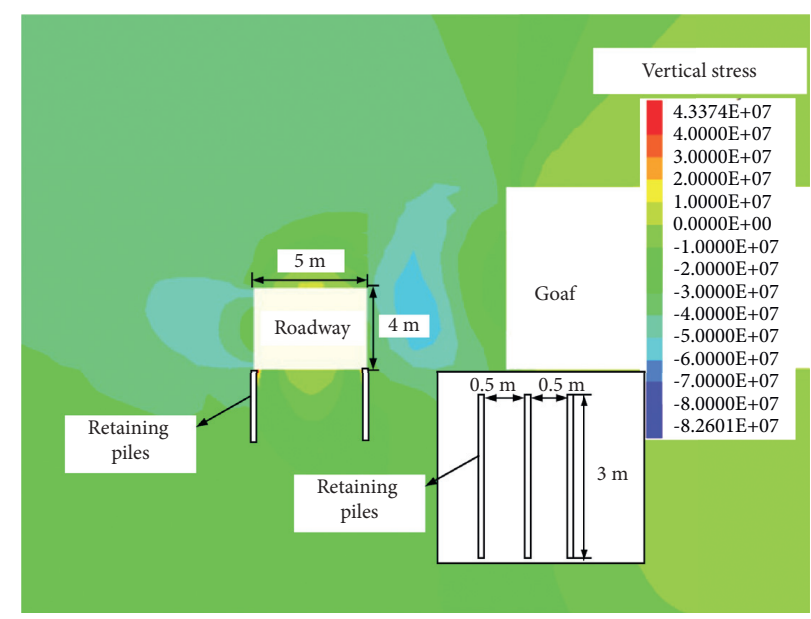

(b)

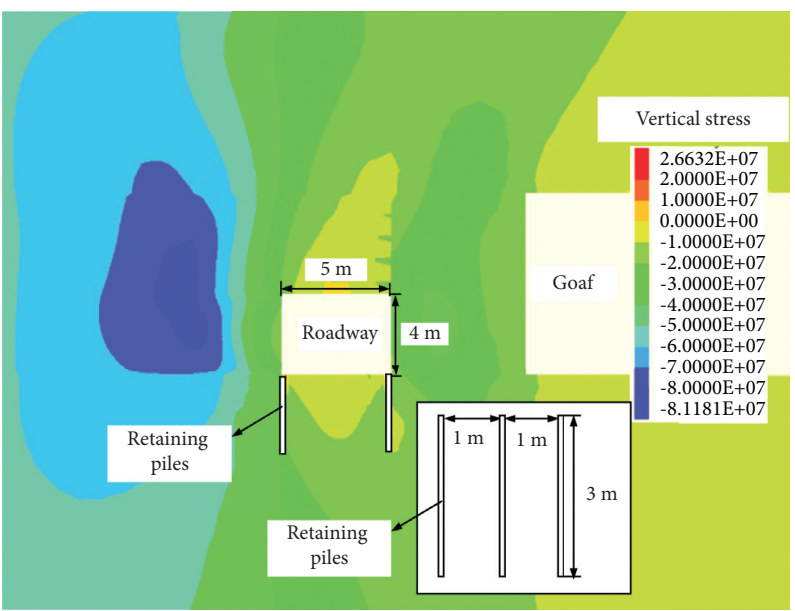

(d)

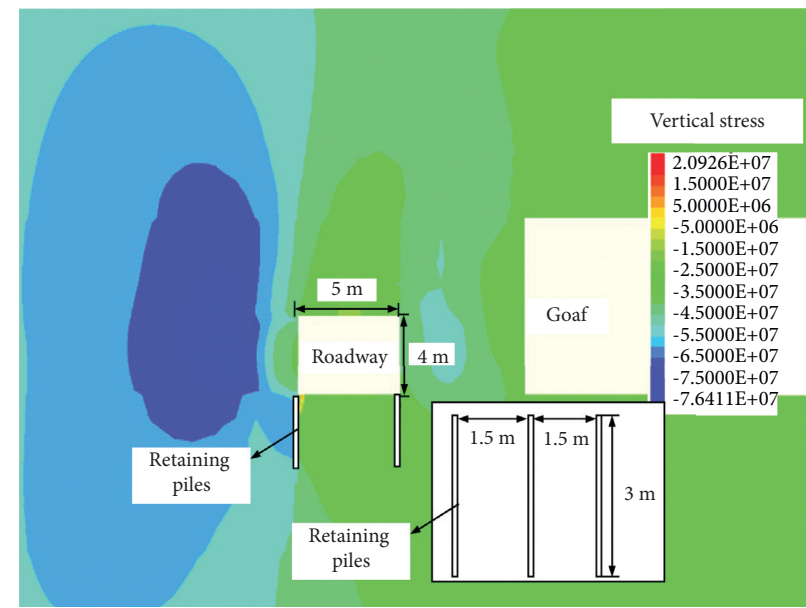

(f)

FIGURE 8: Deformation and stress distribution of roadway surrounding rocks with different spacings of retaining piles. (a) Vertical strain of $0.5 \mathrm{~m}$; (b) vertical stress of $0.5 \mathrm{~m}$; (c) vertical strain of $1.0 \mathrm{~m}$; (d) vertical stress of $1.0 \mathrm{~m}$; (e) vertical strain of $1.5 \mathrm{~m}$; (f) vertical stress of $1.5 \mathrm{~m}$. 


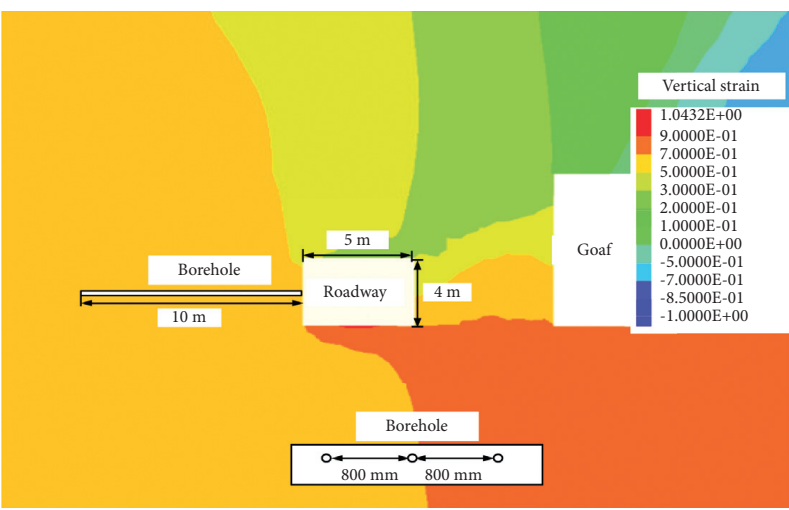

(a)

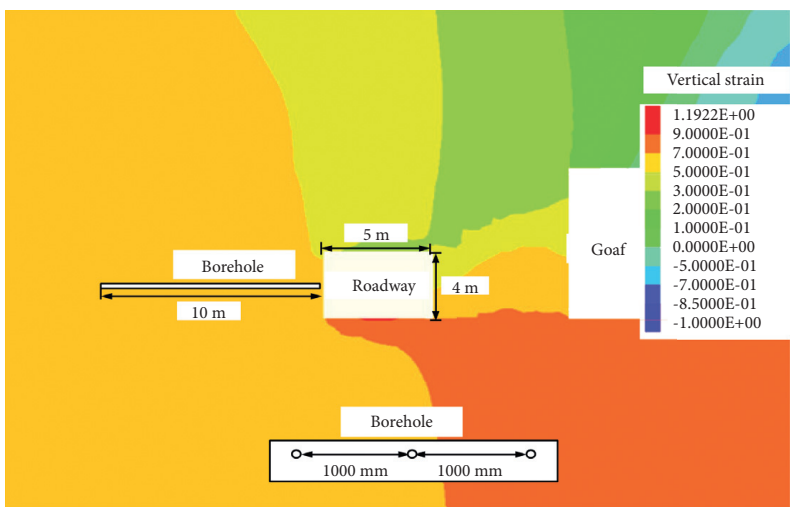

(c)

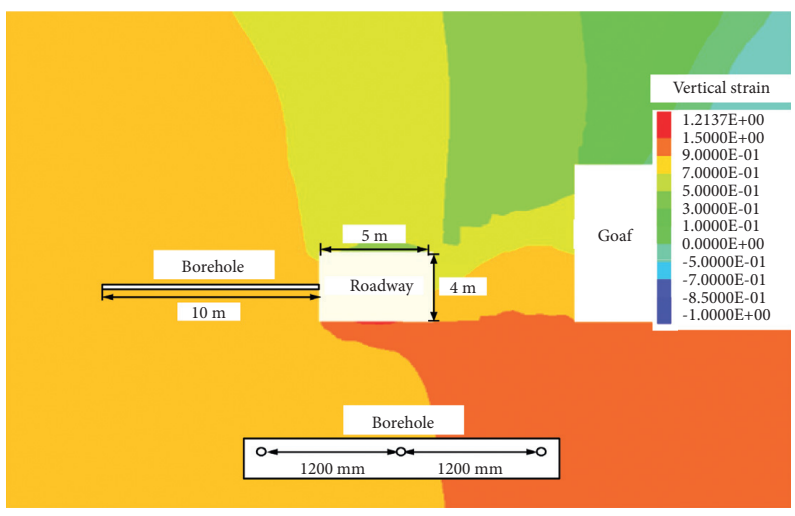

(e)

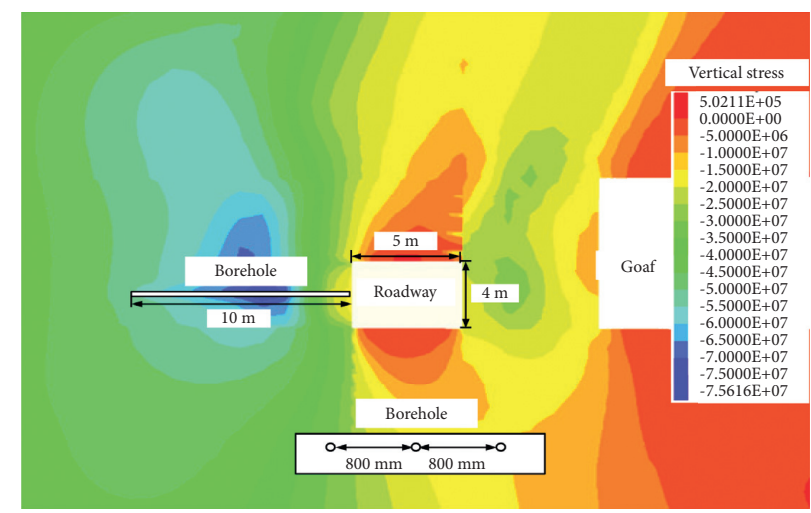

(b)

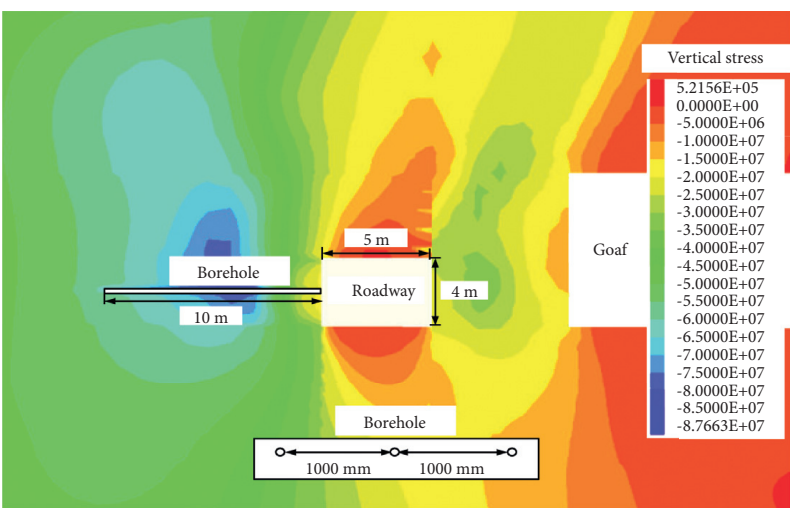

(d)

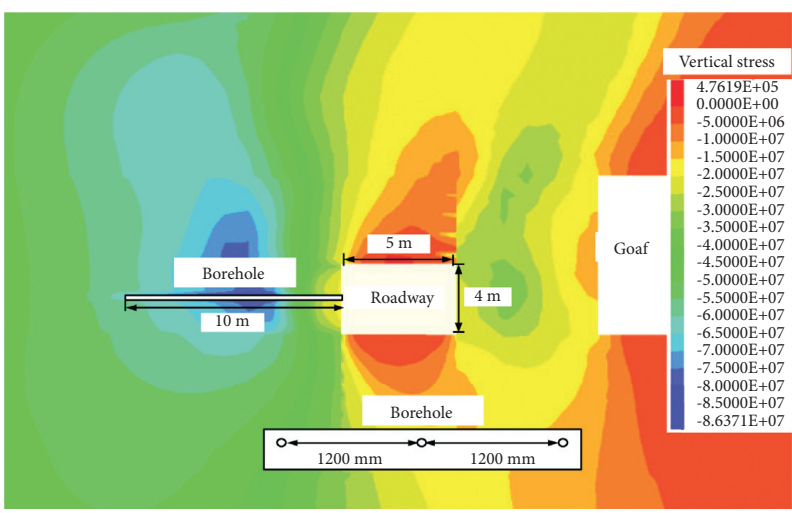

(f)

FiguRE 9: Deformation and stress distribution of surrounding rocks in mining roadway with different spacings of pressure relief boreholes. (a) Vertical strain of $0.8 \mathrm{~m}$; (b) vertical stress of $0.8 \mathrm{~m}$; (c) vertical strain of $1.0 \mathrm{~m}$; (d) vertical stress of $1.0 \mathrm{~m}$; (e) vertical strain of $1.2 \mathrm{~m}$; (f) vertical stress $1.2 \mathrm{~m}$.

\subsection{Deformation Law of Roadway Surrounding Rocks.}

The "cross-bonded method" was used to observe the surface displacement of roadway surrounding rocks, the multipoint displacement meter was used to observe the deep displacement of roadway surrounding rocks, and the roof and floor of roadway are the main monitoring object. The main monitoring results are as follows.
(1) Deformation law of roadway roof and floor

With the mining of no. 130203 working face, the surrounding rocks deformation of return airway shows different changes. The monitoring results of roof falling capacity and floor heave displacement of each station are shown in Figures 11 and 12, respectively. In order to facilitate data comparison, the 


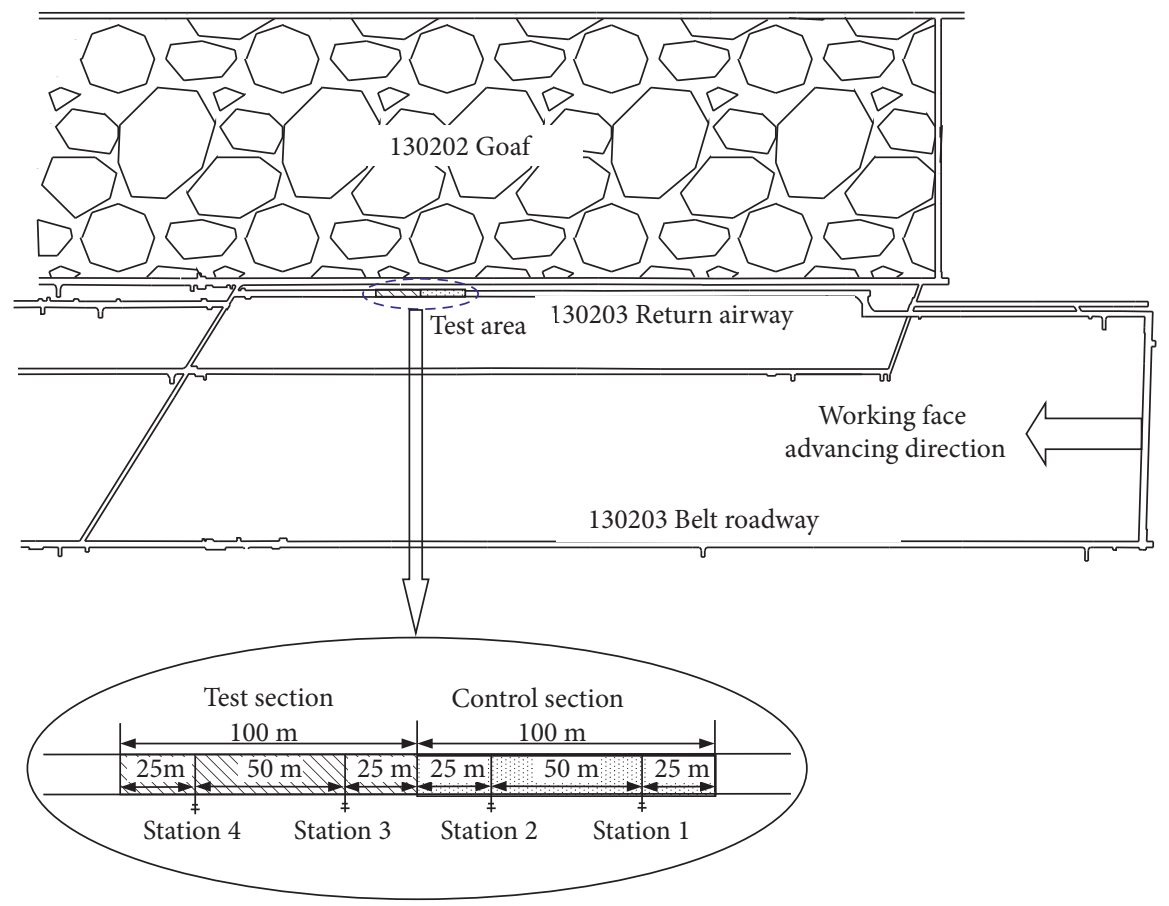

Figure 10: Test area and station layout diagram.

data of each station are recorded at $120 \mathrm{~m}$ from the working face.

It can be seen from Figure 11 that when the measuring point is $80 \mathrm{~m}$ away from the working face, the roof falling capacity of roadway is small. Within the range of $80-30 \mathrm{~m}$ from the working face, the surrounding rocks of the roadway are affected by the advanced abutment pressure, and the roof falling capacity begins to increase significantly. When the distance from the working face is within $30 \mathrm{~m}$, the roof falling capacity of the control section is still increased, and the speed of the roof falling capacity of the test section is gradually slowed down. Thus, the mining roadway is less affected by the mining of the working face outside $80 \mathrm{~m}$ and is in the slow deformation stage. The influence range of the advanced abutment pressure of the working face is $80 \mathrm{~m}$ ahead of the working face.

At the same time, by comparing the change of roof falling capacity of each station, the maximum values of the control section are $1366 \mathrm{~mm}$ and $1364 \mathrm{~mm}$, respectively, with an average of $1365 \mathrm{~mm}$. The maximum values of roof falling capacity in the test section were $598 \mathrm{~mm}$ and $594 \mathrm{~mm}$, respectively, with an average of $596 \mathrm{~mm}$, which were $43.67 \%$ lower than those in the control section, and the control effect was obvious.

By comparing the change of floor heave displacement of each station, it can be seen from Figure 12 that the deformation of floor heave in the initial test section is slightly larger than that in the control section, which is because the integrity of the floor is reduced due to the initial construction. In the process of approaching the working face, the floor heave displacement of the control section increases rapidly, while the increase of the test section is slow, indicating that the measures of the test section begin to play a key role. In addition, compared with the monitoring data of each station, the maximum values of the control section were $1257 \mathrm{~mm}$ and $1267 \mathrm{~mm}$, with an average of $1262 \mathrm{~mm}$. The maximum floor heave displacement of the test section was $414 \mathrm{~mm}$ and $406 \mathrm{~mm}$, with an average of $410 \mathrm{~mm}$, which was $852 \mathrm{~mm}$ lower than that of the control section, and the decrease was $67.49 \%$, indicating that the floor heave displacement of the test section was significantly lower than that of the control section.

At the same time, it can be seen from the control section that the floor heave displacement accounts for a large proportion in the deformation of roadway roof and floor. When the deformation of roadway roof and floor is the largest, the floor heave displacement accounts for about $48.16 \%$ of the roof to floor convergence, while the floor heave displacement of the test section accounts for about $40.99 \%$ of the deformation of roadway, indicating that the floor heave displacement of the test section is effectively reduced due to the implementation of the "reliefretaining" control scheme of floor heave, which has a good control effect on the floor heave of roadway.

(2) Deformation law of thickness increasing value of 0-2 $\mathrm{m}$ floor strata

With the mining of working face, the deformation of surrounding rocks of roadway floor has different 


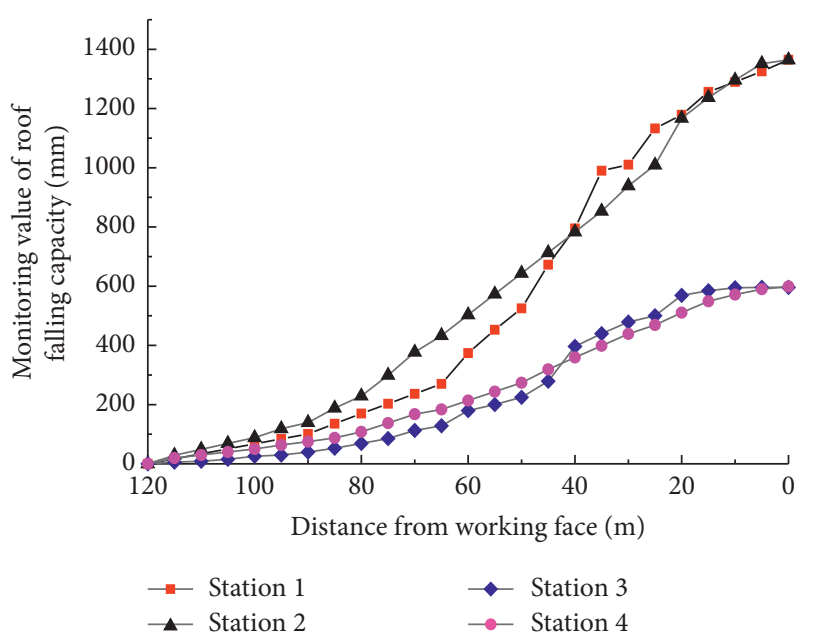

FIgURE 11: Curve diagram of roof falling capacity of each station.

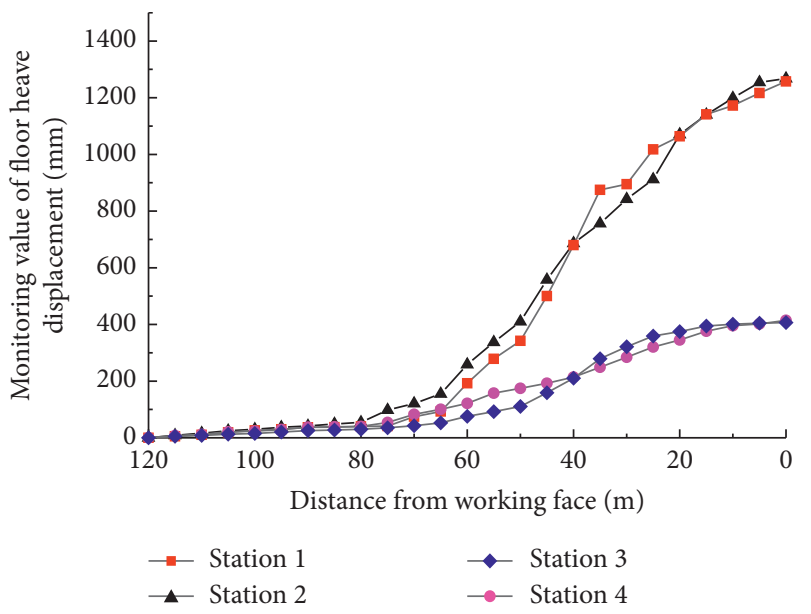

FIGURE 12: Curve diagram of floor heave displacement at each station.

changes. The monitoring results of the average deformation of the surrounding rocks of the roadway floor in the control section and the test section are shown in Figure 13. Because the depth of the cable claw at the deepest point of the multipoint displacement meter of the roadway floor is $2 \mathrm{~m}$, the monitoring data of the deep $2 \mathrm{~m}$ position of the roadway floor are compared and analyzed. At the same time, in order to facilitate data comparison, the data of each station are recorded from $120 \mathrm{~m}$ away from the working face.

Comparing the average change of surrounding rocks of roadway floor between the control section and the test section, it can be seen that before $80 \mathrm{~m}$ from the working face, the deformation trend of surrounding rocks of roadway floor in the test section and the control section is similar, but the deformation speed of the test section is slightly smaller than that of the control section. In the range of $80-50 \mathrm{~m}$ from the working face, the deformation of the test section is still very stable, but the deformation of the control section increases sharply, and the deformation of the surrounding rocks of the roadway floor in the test section is much smaller than that of the control section. Within $50 \mathrm{~m}$, the deformation of the control section slightly slowed down, while the deformation of the test section was still relatively stable and maintained at a low growth state.

From the monitoring data, it can be seen that during the period from $120 \mathrm{~m}$ from the measuring station to the working face until the working face is pushed past the measuring station, the deformation of roadway floor surrounding rocks in the test section was significantly reduced compared with that in the control section. The maximum deformation value of roadway floor surrounding rocks in the control section was $333 \mathrm{~mm}$, and the deformation value of roadway floor surrounding rocks in the test section was $82 \mathrm{~mm}$, which was reduced by $75.38 \%$, indicating that the effect of the "relief-retaining" control scheme of floor heave was significant. 


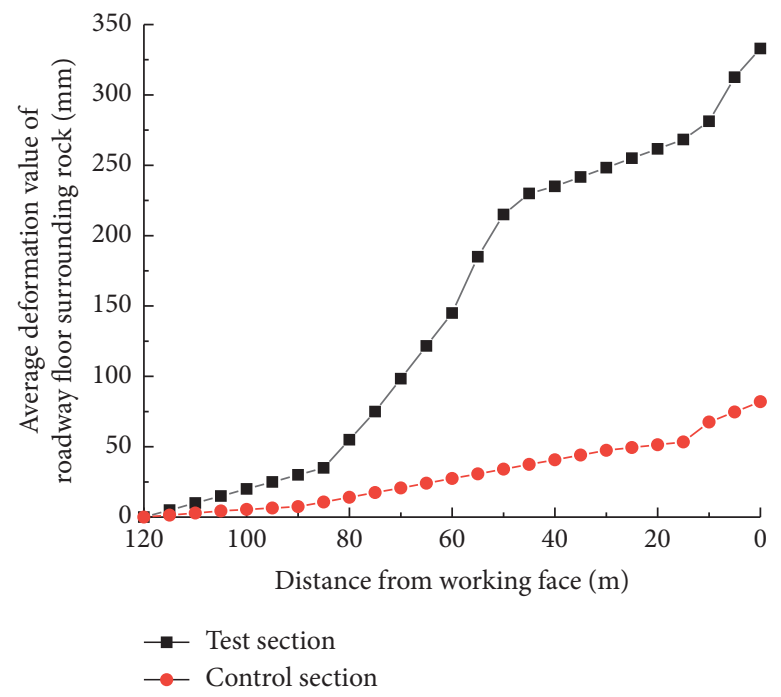

FIGURE 13: The average deformation curves of 0-2 $\mathrm{m}$ floor strata of control section and test section.

\begin{abstract}
After monitoring the station, the deformation of surrounding rocks in different layers of roadway floor is counted, and the deformation of surrounding rocks in different layers of roadway floor is shown in Figure 14. It can be seen from Figure 14 that whether the test section or the control section, the deformation of surrounding rocks of roadway floor gradually decreases with the increase of depth. By comparing the deformation of surrounding rocks in different layers of the test section and the control section, it is found that the deformation of the test section in each layer is smaller than that in the corresponding layer of the control section. The shallower the layer is, the more obvious the reduction effect of the test section scheme is. In particular, the effect is the most obvious when the shallow part is $0-0.5 \mathrm{~m}$. The deformation reduction of the test section is $155 \mathrm{~mm}$, which is $75.61 \%$ lower than that of the control section.
\end{abstract}

4.2. Stress Variation Law of Roadway Surrounding Rocks. In the mining process of no. 130203 working face, the stress of roadway surrounding rocks shows a certain change rule. The MSC-400 cable dynamometer is used to monitor the average stress of roadway surrounding rocks. The monitoring results of the control section and the test section are shown in Figure 15. In order to facilitate data comparison, the data of each station are recorded from $190 \mathrm{~m}$ away from the working face.

It can be seen from the monitoring data that within the range of 30-35 $\mathrm{m}$ from the working face, the cable force in the control section and the test section appears to be the maximum. The maximum force of cable in the control section appears at about $35 \mathrm{~m}$ from the working face, which is about $206.06 \mathrm{kN}$. The maximum force of the cable in the test section appears at about $30 \mathrm{~m}$ from the working face, which is about $140.13 \mathrm{kN}$. Compared with the control section, the test section is reduced by $32.54 \%$, indicating that the "relief-retaining" control scheme of floor heave has a certain effect on reducing the force of surrounding rocks.

4.3. Discussion. The analysis of the above monitoring results shows that the deformation of the surrounding rocks of the mining roadway is effectively controlled after the "reliefretaining" control scheme of floor heave. The floor heave displacement is reduced by $67.49 \%$, and the cable force is reduced by $32.54 \%$. The stress environment and stability of the surrounding rocks are significantly improved, which has played a good demonstration role. The main reason is that the "relief-retaining" control scheme of floor heave liberates the deformation of floor, reduces the stress of surrounding rocks, and effectively blocks the transmission of horizontal stress, which will greatly reduce the deformation and stress of floor.

Many studies have been carried out by many scholars on the floor heave control of roadways with similar conditions $[4,16,28-31]$. For example, Gu et al. [28] proposed the combined support of bolt grouting and grooving to control floor heave for the floor of return airway in 2407 working face of high-stress roadway with soft rock in Yuhua Coal Mine, Tongchuan, and the field monitoring showed that the floor heave displacement was reduced by $61.5 \%$. This not only reduces the impact of horizontal stress but can also lead to difficulty in repairing the floor. Compared with the above scheme, the "relief-retaining" control scheme of floor heave proposed in this paper can effectively reduce the stress concentration degree of roadway side and resist the transmission of horizontal stress of floor, so as to reduce the influence of horizontal stress on floor strata. At the same time, it can provide certain free space for floor deformation and liberate the deformation of roadway floor, so the control effect is better than the above scheme.

In summary, it can be seen that the mechanism of floor heave is likely to be related to the horizontal stress and the 


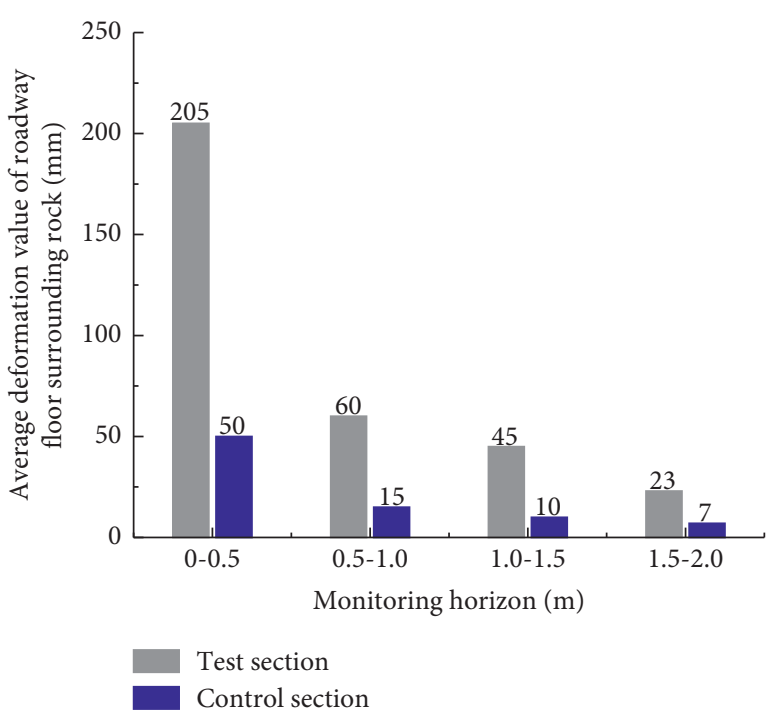

FIGURE 14: Histogram of average deformation value of roadway floor surrounding rocks in different layers.

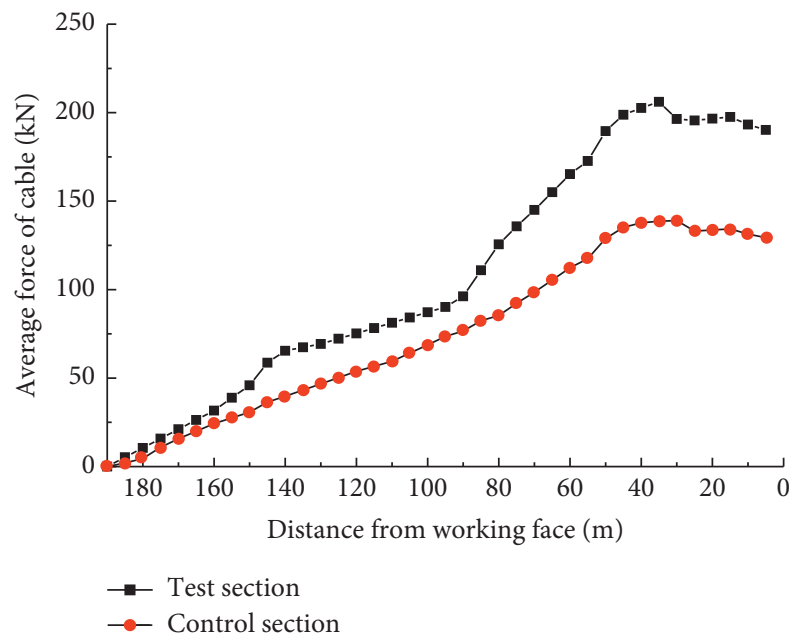

FIGURE 15: Average stress curve of anchor of surrounding rocks of solid coal side of roadway in control section and test section.

stress concentration degree of roadway side and floor. For example, the floor heave can be reduced to a certain extent by reducing the stress concentration by implementing the pressure relief of large-diameter boreholes on roadway side. The next step will focus on these three factors to carry out the related research on the mechanism of floor heave in highstress roadway with soft rock.

\section{Conclusions}

Based on the serious floor heave problem of no. 130203 working face return airway in Zaoquan Coal Mine of Ningdong Mining Area, an innovative "relief-retaining" control scheme of floor heave is designed, and the specific parameters suitable for floor heave control of no. 130203 return airway are determined; then the feasibility of the technical scheme is verified by engineering practice in the field. The main conclusions are as follows.

(1) Taking the typical high-stress soft rock roadway with large deformation in Zaoquan Coal Mine of Ningdong Mining Area as the background, the "reliefretaining" control scheme of floor heave is proposed, which is the comprehensive measure of "cutting groove in floor + drilling for pressure relief at roadway side + setting retaining piles at the junction of roadway side and floor."

(2) The specific parameters suitable for floor heave control of no. 130203 return airway are determined using numerical simulation method. The depth and width of pressure relief groove are $2.0 \mathrm{~m}$ and $0.5 \mathrm{~m}$, respectively. The length and spacing of retaining piles are $3.0 \mathrm{~m}$ and $1.0 \mathrm{~m}$, respectively. The depth and spacing of large-diameter pressure relief boreholes are $10.0 \mathrm{~m}$ and $1.0 \mathrm{~m}$, respectively.

(3) By conducting "relief-retaining" control scheme, field monitoring results show that the average roof falling capacity is $596 \mathrm{~mm}$, and the average floor heave displacement is $410 \mathrm{~mm}$, which are, respectively, $43.67 \%$ and $67.49 \%$ less than the control section. The maximum force of cable is about $140.13 \mathrm{kN}$, which is $32.54 \%$ less. The deformation and failure of roadway surrounding rocks, especially floor heave, are well controlled.

\section{Data Availability}

The data used to support the findings of this study are available from the corresponding author upon request.

\section{Conflicts of Interest}

The authors declare no conflicts of interest.

\section{Acknowledgments}

The authors would like to thank reviewers and editors for their kind work. The authors gratefully acknowledge financial support from the National Natural Science Foundation of China (nos. 51804181, 51874190, and 52074168) and the Climbing Project of Taishan Scholar in Shandong Province (no. tspd20210313).

\section{References}

[1] J. Shi and D. Kong, "Floor heave mechanism and anti-slide piles control technology in deep and large-span chamber," Applied Sciences, vol. 11, no. 10, p. 4576, 2021.

[2] H. Jia, L. Wang, K. Fan, B. Peng, and K. Pan, "Control technology of soft rock floor in mining roadway with coal pillar protection: a case study," Energies, vol. 12, no. 15, p. 3009, 2019.

[3] C. Wang, Y. P. Wu, S. J. Chen et al., "Analysis and application on inverted arch support of cross-cut floor heave," Journal of Physics: Conference Series, vol. 2002, no. 1, pp. 713-720, 2021.

[4] X. Kang, D. Guo, and Z. Lu, "Mechanism of roadway floor heave controlled by floor corner pile in deep roadway under 
high horizontal stress," Advances in Civil Engineering, vol. 2021, Article ID 6669233, 10 pages, 2021.

[5] W. Zheng, Y. Zhao, Q. Bu, and S. I. Kundalwal, "The coupled control of floor heave based on a composite structure consisting of bolts and concrete antiarches," Mathematical Problems in Engineering, vol. 2018, Article ID 3545423, 14 pages, 2018.

[6] M. C. He, G. F. Zhang, G. L. Wang, Y. L. Xu, C. Z. Wu, and Q. D. Tang, "Research on mechanism and application to floor heave control of deep gateway," Chinese Journal of Rock Mechanics and Engineering, vol. 28, pp. 2593-2598, 2009.

[7] J. Sun and L. Wang, "Numerical simulation of grooving method for floor heave control in soft rock roadway," Mining Science and Technology (China), vol. 21, no. 1, pp. 49-56, 2011.

[8] J. B. Bai, W. F. Li, X. Y. Wang, X. U. Ying, and L. J. Huo, "Mechanism of floor heave and control technology of road way induced by mining," Journal of Mining and Safety Engineering, vol. 28, pp. 1-5, 2011.

[9] Y. J. Li, "Study on mechanism analysis and control technology of roadway floor heave," Coal Chemical Industry, vol. 40, pp. 31-33, 2017.

[10] X. Q. Wang, J. G. Kan, and J. K. Jiao, "Mechanism of floor heave in the roadway with high stress and soft rock and its control practice," Journal of Mining and Safety Engineering, vol. 38, pp. 215-226, 2021.

[11] G. M. Chen, Y. T. Zhang, H. H. He, and H. W. Zhang, "Research on mechanism and control technology of floor heave in soft rock roadway in Dafosi mine," China Coal, vol. 39, pp. 59-61, 2013.

[12] C. Wang, Y. Wang, and S. Lu, "Deformational behaviour of roadways in soft rocks in underground coal mines and principles for stability control," International Journal of Rock Mechanics and Mining, vol. 37, 2000.

[13] J. C. Stankus and S. S. Peng, "Floor bolting for control of mine floor heave," Mining Engineering, vol. 46, pp. 1099-1102, 1994.

[14] P. T. Xie, "Reinforcement design and application on close roadway below mined - out area," Shanxi Coking Coal Science Technology, vol. 37, pp. 8-10+14, 2013.

[15] X. S. Liu, D. Y. Fan, Y. L. Tan et al., "Failure evolution and instability mechanism of surrounding rock for close-distance parallel chambers with super-large section in deep coal mines," International Journal of Geomechanics, vol. 21, 2021.

[16] L. Shi, H. D. Zhang, and P. Wang, "Research on key technologies of floor heave control in soft rock roadway," $A d$ vances in Civil Engineering, vol. 2020, Article ID 8857873, 13 pages, 2020.

[17] W. X. Zheng, Q. W. Bu, and Y. Q. Hu, "Plastic failure analysis of roadway floor surrounding rocks based on unified strength theory," Advances in Civil Engineering, vol. 2018, Article ID 7475698, 10 pages, 2018.

[18] X. Liu, S. Song, Y. Tan et al., "Similar simulation study on the deformation and failure of surrounding rock of a large section chamber group under dynamic loading," International Journal of Mining Science and Technology, vol. 31, no. 3, pp. 495-505, 2021.

[19] X. S. Liu, D. Y. Fan, Y. L. Tan et al., "New detecting method on the connecting fractured zone above the coal face and a case study," Rock Mechanics and Rock Engineering, vol. 54, no. 8, pp. 4379-4391, 2021.

[20] H. Zhang, H. P. Kang, and Y. L. Xu, "Study on rapid reinforced technology with pre-stressed anchor for floor of mine roadway in deep mine," Coal Science and Technology, vol. 41, pp. 16-19+23, 2013.
[21] L. Z. Xu and S. J. Wei, "Control technology and simulation study of floor heave in high stress soft rock roadway," Geotechnical \& Geological Engineering, vol. 38, pp. 1-14, 2020.

[22] H. P. Kang, J. H. Wang, and J. Lin, "Study and applications of roadway support techniques for coal mines," Journal of China Coal Society, vol. 35, pp. 1809-1814, 2010.

[23] T. Yang and J. Zhang, "Research on the treatment technology of soft rock floor heave based on a model of pressure-relief slots," Arabian Journal Geosciences, vol. 14, 2021.

[24] D. Y. Fan, X. S. Liu, Y. L. Tan et al., "Roof cutting parameters design for gob-side entry in deep coal mine: a case study," Energies, vol. 12, 2019.

[25] M. G. Qian, P. W. Shi, and J. L. Xu, Ground Pressure and Strata Control, China University Min Techno Press, Beijing, China, 2010.

[26] S. G. Liu, J. B. Bai, X. Y. Wang, B. W. Wu, W. D. Wu, and Z. X. Li, "Mechanisms of floor heave in roadways adjacent to a goaf caused by the fracturing of a competent roof and controlling technology," Shock and Vibration, vol. 2020, Article ID 5632943, 17 pages, 2020.

[27] D. Y. Fan, X. S. Liu, Y. L. Tan, S. L. Song, J. G. Ning, and Q. Ma, "Numerical simulation research on response characteristics of surrounding rock for deep super-large section chamber under dynamic and static combined loading condition," Journal of Central South University, vol. 27, no. 12, pp. 3544-3566, 2020.

[28] S. C. Gu, X. M. Wang, R. B. Huang, and H. W. He, "Analysis on mechanism and control technique of floor heave deformation in high stress roadway," Journal Safety Science and Technology, vol. 16, pp. 57-63, 2020.

[29] J. Yang, K. Zhou, Y. Cheng, Y. Gao, Q. Wei, and Y. Hu, "Mechanism and control of roadway floor heave in the paleogene soft rock surroundings," Geotechnical \& Geological Engineering, vol. 37, no. 6, pp. 5167-5185, 2019.

[30] G. Y. Yu, J. Wang, J. Z. Hu et al., "Innovative control technique for the floor heave in goaf-side entry retaining based on pressure relief by roof cutting," Mathematical Problems in Engineering, vol. 2021, Article ID 7163598, 17 pages, 2021.

[31] G. R. Feng, S. Y. Li, P. F. Wang et al., "Study on floor mechanical failure characteristics and stress evolution in double predriven recovery rooms," Mathematical Problems in Engineering, vol. 2020, Article ID 9391309, 13 pages, 2020. 